\title{
PROCESSAMENTO DE DADOS AEROGEOFÍSICOS E DE SUSCEPTIBILIDADE MAGNÉTICA EM UMA TRANSECTA NW, NA BORDA SUL DO ESCUDO SUL RIOGRANDENSE, RIO GRANDE DO SUL - BRASIL.
}

\author{
Renato Luiz da Silveira ${ }^{1}$, Mario Jesus Tomas Rosales ${ }^{1}$, Cristiane Heredia Gomes ${ }^{1}$, Mateus Arantes ${ }^{1}$, Dione Fontoura ${ }^{1}$, Suze \\ Nei Pereira Guimarães ${ }^{2}$.
}

Universidade Federal do Pampa ${ }^{1}$, ON/MCTI²

Copyright 2014, SBGf - Sociedade Brasileira de Geofísica

Este texto foi preparado para a apresentação no VI Simpósio Brasileiro de Geofísica, Porto Alegre, 14 a 16 de outubro de 2014. Seu conteúdo foi revisado pelo Comitê Técnico do VI SimBGf, mas não necessariamente representa a opinião da SBGf ou associados. É proibida a reprodução total ou parcial deste material para propósitos comerciais sem prévia autorização da SBGt.

\section{Resumo}

Este trabalho consistiu na utilização dos métodos geofísicos de prospecção, (magnetometria e gamaespectrometria) através do processamento de dados compilados do Projeto Aerogeofísico Escudo do Rio Grande (CPRM, 2010), conjuntamente com dados de susceptibilidade magnética e de gamaespectrometria terrestres aquiridos em campo, visando à atualização do mapeamento geofísico e geológico das rochas pertencentes a porção Sul do Escudo Sul Rio-grandense (ESRG) em contato com rochas da Bacia do Paraná. A área da pesquisa apresenta aproximadamente 38680 km² $^{2}$ localizada no extremo sul do Estado do Rio Grande do Sul - Brasil. Refere-se a uma Transecta na direção NW abrangendo uma porção territorial dos municípios de Dom Pedrito, Bagé, Hulha Negra e Candiota. Os principais domínios geológicos que aparecem expostos na área, referem-se às rochas da Formação Rio Bonito ( 285 Ma), localizado na porção leste. A porção sul se encontra caraterizada por um domínio marcado por um trend de falhas de direção NE-SW, associado as rochas da Formação Irati ( 260 Ma). Na porção central da área destacam-se dois domínios estendidos na direção W-E dispostos de maneira subparalela, ao norte, caracterizado por rochas pertencentes ao Complexo granito-gnáissico Bagé ( 640 Ma), ao sul, caraterizado por rochas pertencentes à formação Estrada Novas ( $255 \mathrm{Ma})$. Na porção noroeste da área afloram rochas pertencentes à suíte granítica Campinas ( 605 Ma) afetada tectonicamente por falhas orientadas na direção NW. Foram confeccionados produtos geofísicos tais como, mapas da anomalia residual magnética de intensidade total e mapas oriundos das transformações do campo potencial sobre os dados da anomalia residual magnética, tais como: Continuação para cima (500 m), Gradiente Horizontal e Amplitude do Sinal Analítico. Para os dados gamaespectrométricos foram confeccionados mapas de imagens dos canais de $\mathrm{K}(\%)$, eU (ppm), eTh (ppm) e de Contagem Total (ppm), assim como mapas das razões dos radioelementos, mapa ternário (RGB) e mapa do fator $(F)$. Como resultados principais pode destacar-se a identificação e caracterização geofísica de domínios magnetométricos em escala regional a partir da interpretação dos mapas obtidos das transformações realizadas ao campo potencial de anomalias magnéticas de intensidade total, associados a feições geológicas e estruturais mapeadas e verificadas no campo através do reconhecimento geológico. A interpretação qualitativa e semi-quantitativa dos dados geofísicos permitiu identificar o contato entre as rochas do embasamento compostas por gnaisses e as rochas sedimentares pertencentes à Bacia do Paraná

\section{Introdução}

$\mathrm{Na}$ presente pesquisa foram utilizados métodos geofísicos de prospecção, (magnetometria e gamaespectrometria) através do processamento de dados compilados do Projeto Aerogeofísico Escudo do Rio Grande (CPRM, 2010), conjuntamente com dados de susceptibilidade magnética e de gamaespectrometria terrestre adquiridos em campo, visando à atualização do mapeamento geofísico e geológico das rochas pertencentes à porção Sul do Escudo Sul Rio-grandense (ESRG) em contato com rochas da Bacia do Paraná.

\section{Área de Estudo}

A área da pesquisa apresenta aproximadamente 38680 $\mathrm{km}^{2}$, localizada no extremo sul do Estado do Rio Grande do Sul - Brasil é delimitado geograficamente pelas Longitudes: $54^{\circ} 30^{\prime} 42.9055^{\prime \prime} \mathrm{W}, 53^{\circ} 34^{\prime} 18.1691 " \mathrm{~W}$ e pelas Latitudes: $30^{\circ} 59^{\prime} 43.5062^{\prime \prime} \mathrm{S}, 31^{\circ} 47^{\prime} 39.1179$ " S. Refere-se a uma Transecta na direção NW abrangendo uma porção territorial dos municípios de Dom Pedrito, Bagé, Hulha Negra e Candiota. Está localizada a 393 km da capital Porto Alegre (Fig.1).

\section{Arcabouço geológico}

A área correspondente a Transecta na direção NW, se encontra localizada geologicamente na borda sul do ESRG, abrangendo principalmente rochas dos domínios Taquarembó, Bacia do Camaquã e Província do Paraná. Segundo o mapa geológico da CPRM (2008), (Fig. 2), na área de estudo afloram doze unidades litoestratigráficas de idades Pré-cambrianas ao Neógeno. Estas unidades foram subdivididas em quatro principais domínios geológicos que aparecem expostos na área, referem-se à Formação Rio Bonito ( 285 Ma), localizado na porção leste, é constituída por siltitos, arenitos finos a muito finos e folhelhos. 


\section{Processamento de dados Aerogeofísicos e de Susceptibilidade Magnética em uma 2 Transecta NW}

A porção sul se encontra caraterizada por um domínio marcado por um trend de falhas de direção NE-SW, associados às Formações Irati ( 260 Ma) e Estrada Nova, constituída folhelho, siltíto e argilito, calcário, marga geralmente tabular ou lenticulado alongado.

$\mathrm{Na}$ porção central da área destacam-se dois domínios estendidos na direção W-E dispostos de maneira subparalela, ao norte, caraterizado por rochas pertencentes ao Complexo granito-gnáissico Bagé ( 640 $\mathrm{Ma})$, ao sul, caraterizado por rochas pertencentes a $\mathrm{Fm}$. Estrada Nova ( 255 Ma). Na porção noroeste da área afloram rochas pertencentes à suíte granítica Campinas ( 605 Ma) afetada tectonicamente por falhas orientadas na direção NW.

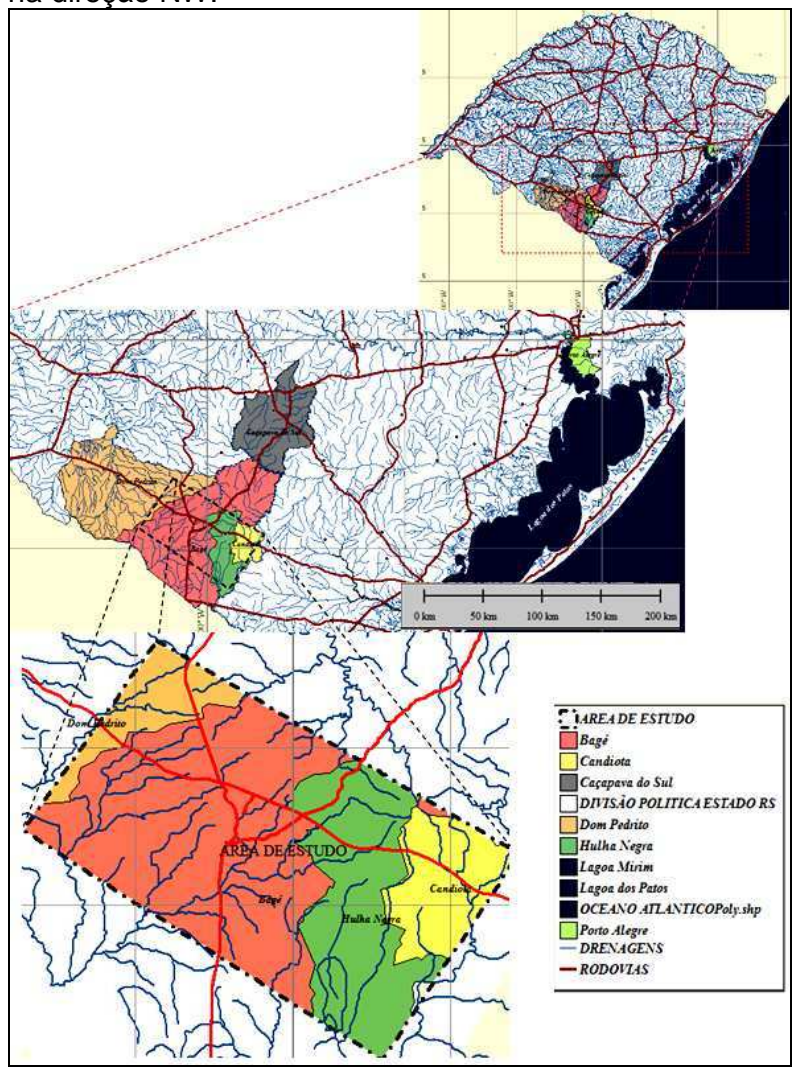

Figura 1- Mapa esquemático de localização da área de estudo modificado de CPRM (2008).

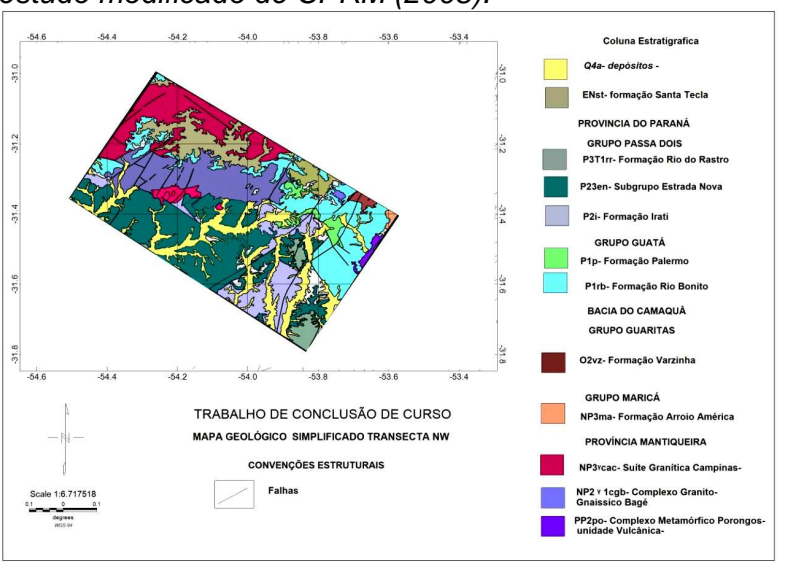

Figura 2- Mapa geológico simplificado da Transecta NW modificado de CPRM (2008).

Dados Compilados

O Projeto Aerogeofísico Escudo do Rio Grande do Sul, (CPRM, 2010) constou do recobrimento de 159.789,21 km de perfis aerogeofísicos de alta resolução, com linhas de voos e controle espaçado a $500 \mathrm{~m}$ e $10 \mathrm{~km}$ respectivamente, orientadas nas direções N-S e EW, respectivamente.

O mapa da (Fig.3), ilustra o posicionamento das linhas de voos distribuídas sobre a poligonal envoltória da área correspondente ao Estado do Rio Grande do Sul, assim como o contorno que delimita a área de estudo da presente pesquisa referente à Transecta NW localizada na porção sudoeste do mapa.

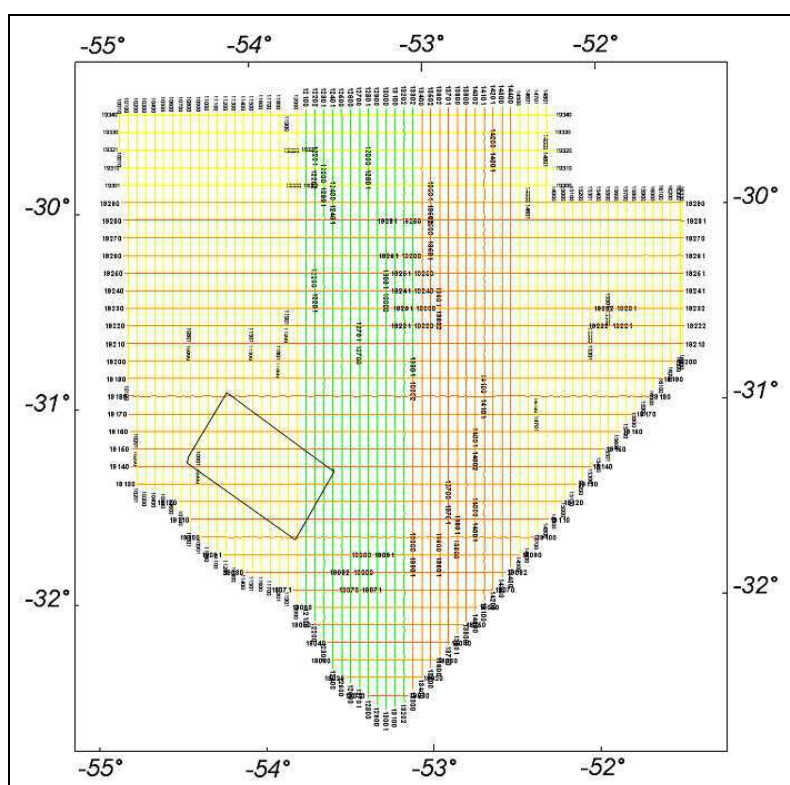

Figura 3- Mapa esquemático das linhas de vôos do projeto Aerogeofísico Escudo do Rio Grande do Sul (CPRM, 2010) mostrando o contorno que delimita a área de estudo referente à Transecta NW.

\section{Modelo Digital de Elevação do Terreno (DEM)}

Os dados topográficos provenientes do ASTER GDEM oferecem uma resolução espacial em longitude e latitude de 1 arc-second ( 30 metros) e uma 50 resolução na vertical referente à altitude ortométrica de 7 a 14 metros, aproximadamente.

A Figura 4 mostra um modelo digital de elevação do terreno (DEM) baseado em dados topográficos ASTER$G D E M$, integrado com contornos geológicos para a área de estudo onde se observa que as maiores elevações estão localizadas ao norte da área, com valores de cota de 200 a 360 metros, associadas a rochas pertencentes ao embasamento do (ESRG). Na porção sul da área encontra-se as cotas mais baixas com valores de 119 a 199 metros, associada a rochas da Bacia do Paraná. 


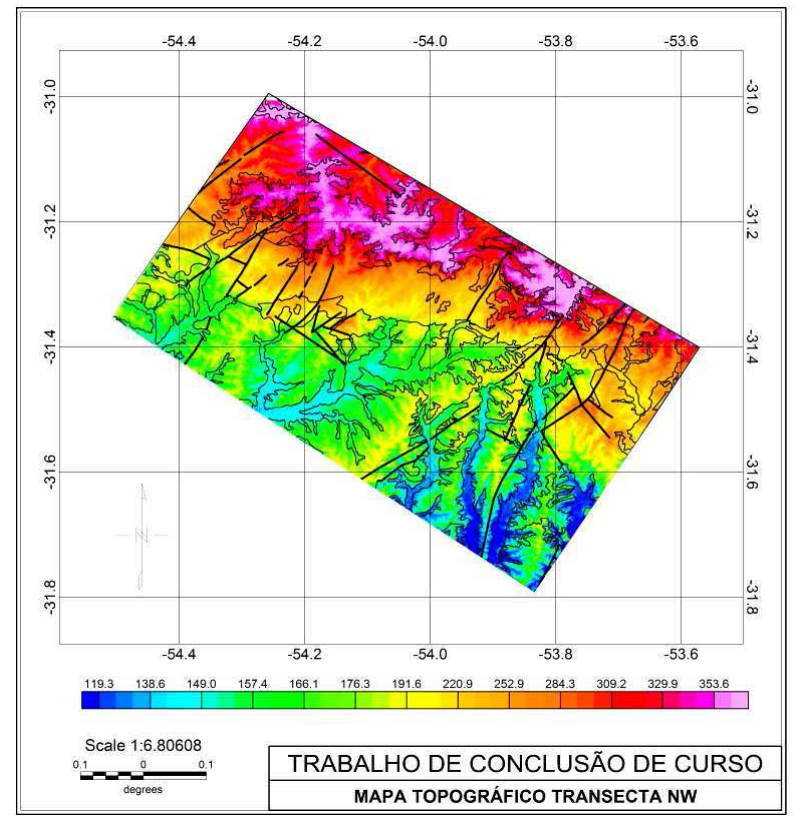

Figura 4- Modelo digital de elevação do terreno baseado em dados ASTER-GDEM para a área de estudo.

\section{Processamento dos Dados Aerogeofísicos}

Os dados do Projeto Aerogeofísico Escudo do Rio Grande do Sul (CPRM, 2010) foram disponibilizados no formato ASCII (XYZ), GDB's, compatíveis com a plataforma do OASIS MONTAJ (GEOSOFT, 2007) onde estão agrupadas informações de posicionamento corrigidas e todos os demais canais de informação registrados a bordo da aeronave.

Foram compilados dados aeromagnéticos provenientes do Projeto Aerogeofísico Escudo do Rio Grande do Sul, (CPRM, 2010). Com a utilização de técnicas de processamento e filtragem aplicadas aos citados dados, foi possível a identificação e realce de assinaturas anômalas nos mapas das diferentes transformações do campo potencial magnético.

Os dados aerogeofísicos foram interpolados utilizando mínima curvatura com uma célula de tamanho de 125 metros, ou seja, 1/4 do espaçamento entre as linhas vôo.

Nesta etapa correspondente ao tratamento e processamento dos dados aeromagnetometricos, envolveu a aplicação de filtros para gerar os mapas de transformações do campo potencial magnético relativa à compilação dos dados CPRM (2010).

\section{Resultados}

A Figura 12 mostra um fluxograma esquemático com o procedimento aplicado ao processamento dos dados aerogeofísicos, onde foram gerados mapas de imagens para gamaespectrometria dos valores anômalos das concentrações dos radioelementos, isto e: mapa do canal do Potássio K (\%), mapa do canal equivalente de Urânio eU (ppm), mapa do canal equivalente de eTh (ppm), mapa de Contagem total (ppm), mapa de Razões eTh/K e eU/K, mapa ternário de composição colorida ( R - K, G eTh e B - eU) e Mapa do Fator F (F = K * eU/eTh).Para magnetometria mapas de imagens representando os procedimentos das técnicas de filtragens utilizadas no processamento dos dados aeromagnetométricos e os produtos gráficos obtidos como resultado final da aplicação dos diferentes filtros (i.e., mapas de imagens das anomalias magnéticas).

Potássio - K (\%)

A Figura 5 mostra as concentrações de K (\%) observadas no mapa, destacam-se altos valores na ordem de $3.6 \%$ presentes numa faixa segundo $\mathrm{E}-\mathrm{W}$ ao norte e ao centro da área, associados aos litotipos do Granito Campinas e a rochas do embasamento granítico gnáissico Bagé.

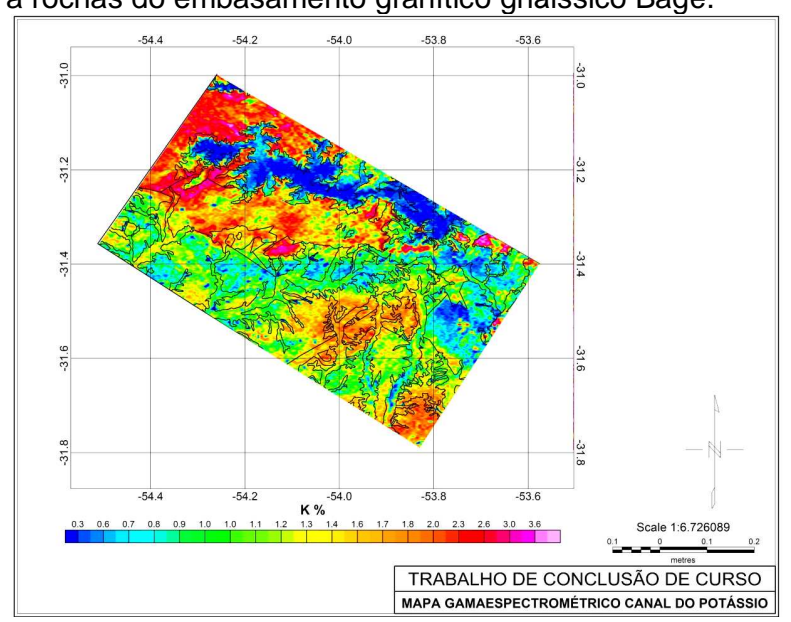

Figura 5-Mapa de imagem para o canal de K (\%).

\section{Equivalente de Urânio - eU (ppm)}

As concentrações de eU (ppm) observadas no mapa da Figura 6 mostram altos valores na porção sudeste da área, associados ao folhelhos da Fm. Irati.

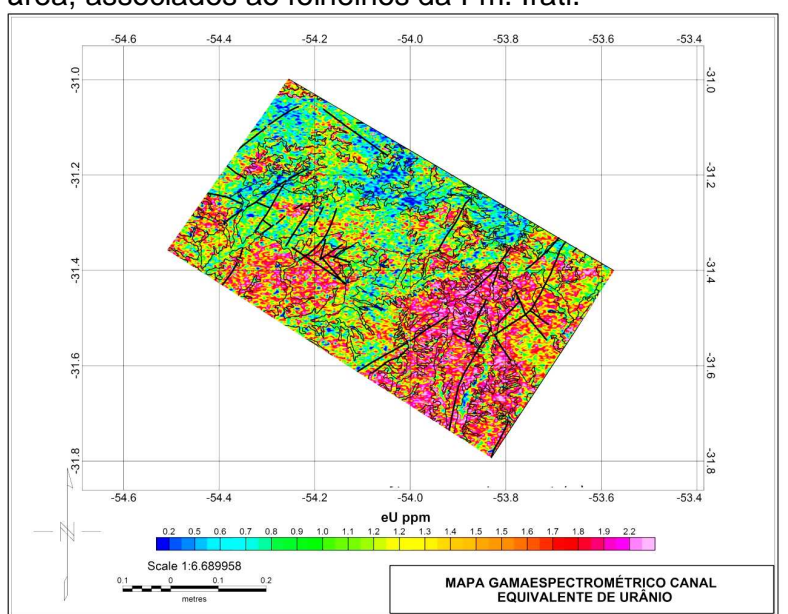

Figura 6- Mapa de imagem para o canal eU (ppm).

\section{Equivalente de Tório - eTh (ppm)}

A Figura 7 mostra o mapa de imagem das concentrações de eTh (ppm) para a área de estudo. Ressalta-se nas 


\section{Processamento de dados Aerogeofísicos e de Susceptibilidade Magnética em uma 4 Transecta NW}

porções sudeste e sudoeste a presença de altos valores em torno de 11 ppm - 14.7 ppm, associada provavelmente a presença de argilominerais contendo hidróxidos de ferro em rochas das Formações Irati e Estrada Nova.

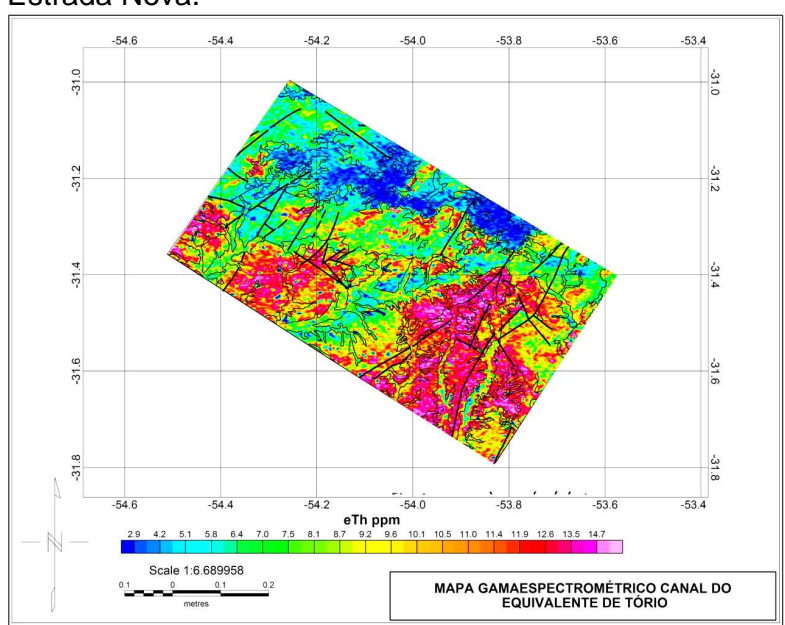

Figura 7- Mapa de imagem para o canal eTh (ppm).

\section{Anomalia Residual Magnética de Intensidade Total}

Conforme se ilustra na Figura 8, o comportamento da anomalia magnética residual apresentou uma resolução superior em termos de identificação e de realce de assinaturas anômalas magnéticas de longo comprimento de onda. Na porção central da área o comportamento da anomalia residual magnética se caracteriza pela presença de um par anômalo magnético com uma direção preferencial segundo E-W, apresentando um sinal positivo ao norte e um sinal negativo ao sul com valores de amplitude variando desde - $86 \mathrm{nT}$ a $+60.7 \mathrm{nT}$. $\mathrm{Na}$ porção sul da área de estudo o comportamento do campo magnético é caracterizado pela presença de uma assinatura magnética de longo comprimento de onda provavelmente associada a fontes localizadas nas rochas do embasamento da Bacia do Paraná.

\section{1․ Derivada no eixo $Z$.}

A Figura 9 apresenta o mapa monocromático da $1^{\text {a }}$ Derivada em " $Z$ " do campo magnético Total, onde a partir de critérios interpretativos permitiu-se identificar lineamentos magnéticos regionais que podem estar associados a zonas de fraqueza tectônica que podem possuir controle estrutural, neste caso, por trends segundo a direção NE-SW.

Amplitude do Sinal Analítico da Anomalia Residual Magnética de Intensidade Total.

A partir dos resultados obtidos da interpretação do mapa da anomalia magnética da Amplitude do Sinal Analítico (ASA), conforme ilustrado na Figura 10 identificou-se assinaturas magnéticas anômalas com um eixo principal na direção E-W na porção central da área de estudo, associadas a rochas pertencentes ao embasamento gnáissico, também se observam feições anômalas isoladas de curto comprimento de onda a sudeste da área, associados à presença provavelmente de diques de composição básica intrudidos em rochas das formações Estrada Nova e Irati da Bacia do Paraná.

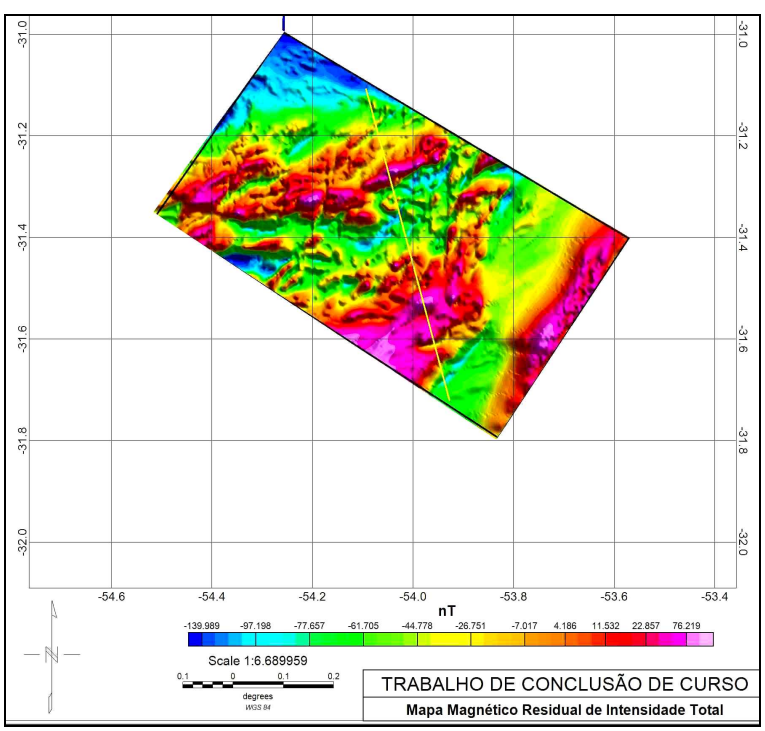

Figura 8- Mapa de imagem da Anomalia Residual Magnética de Intensidade Total

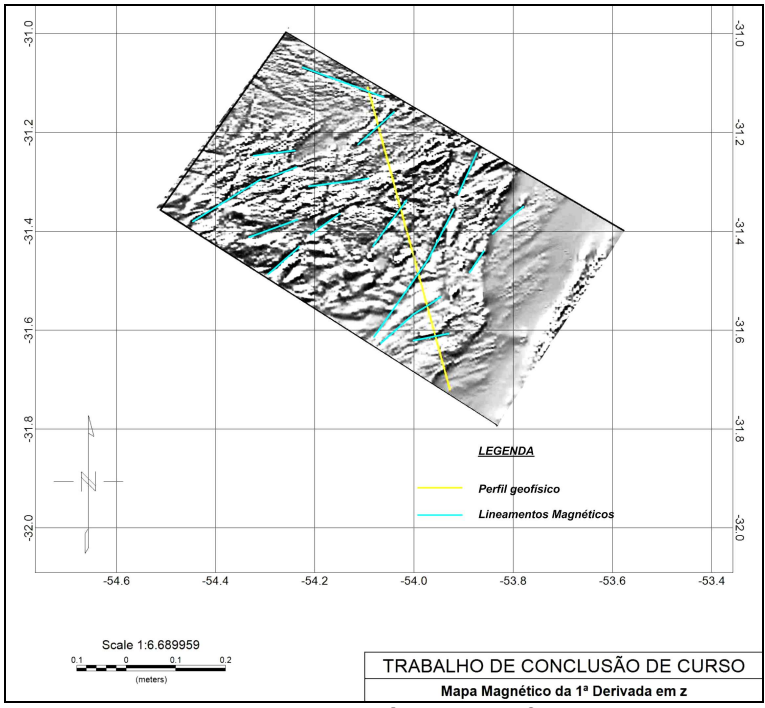

Figura 9- Mapa monocromático da $1^{a}$ Derivada no eixo "Z" da Anomalia Residual Magnética de Intensidade Total.

\section{Mapa geofísico estrutural da Área de Estudo}

A Figura 11 apresenta um mapa geofísico estrutural preliminar proposto para a área de estudo, obtido a partir da integração e interpretação dos produtos geofísicos gráficos oriundos das transformações do campo magnético anômalo, integrado com dados geológicos da CPRM (2008) e os dados de suscetibilidade magnética medidos em campo. Onde se destacam a presença de 
lineamentos magnéticos associados provavelmente a falhamentos geológicos de caráter regional, préexistentes na área, além de outros lineamentos que identificam a presença de novas estruturas geológicas ainda por mapear.

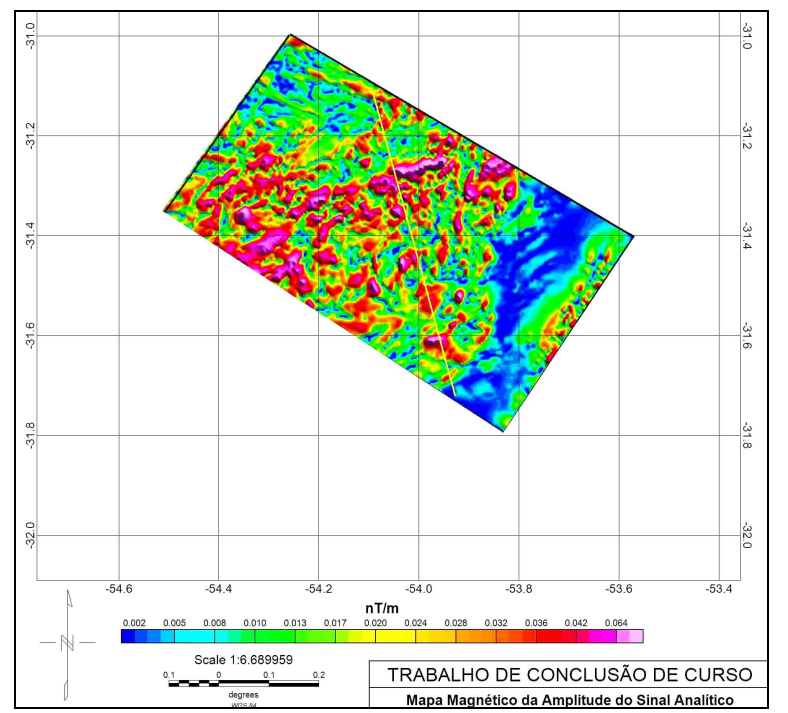

Figura 10- Mapa de imagem da Amplitude do Sinal Analítico da Anomalia residual de Intensidade total.

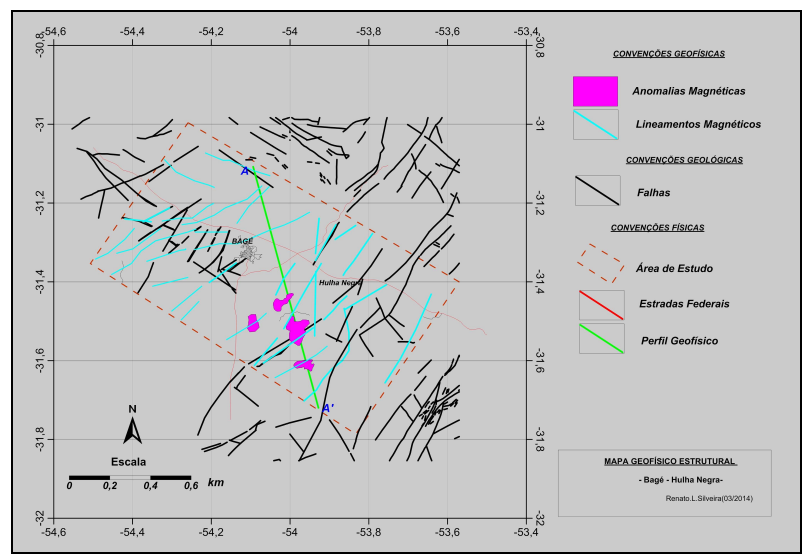

Figura 11- Mapa esquemático preliminar geofísico estrutural proposto para a área de estudo.

\section{Integração de Dados Geofísicos, Geológicos e Topográficos.}

A Figura 13 mostra de uma maneira integrada os gráficos relacionados com o comportamento das concentrações dos radiolementos, bem como resultados anomalias magnéticas conjuntamente com o relevo topográfico. $A$ integração da Amplitude do Sinal Analítico do campo magnético residual de intensidade total, o do Gradiente Horizontal do campo magnético residual de intensidade total apresentam anomalias de curto comprimento de onda das assinaturas magnéticas podem estar associadas a zonas de falha e a diques básicos da Bacia do Paraná.
Aos dados gamaespectrométricos integrados com 0 relevo topográfico e dados geológicos revelam, que a gamaespectrometria é extremamente eficiente na identificação e delimitação espacial de diferentes litológias. No perfil integrado fica bem evidenciado o contato entre os diferentes litotípos nos dados correspondentes aos radioelementos, principalmente 0 canal do Potássio.

\section{Discussão e Conclusões}

Os resultados obtidos no trabalho se mostram consistentes do ponto de vista de interpretação geológico-geofísica, integrando os resultados obtidos a partir dos produtos geofísicos finais do processamento e integração dos dados aerogeofísicos que geraram gráficos da anomalia magnética de intensidade total e suas respectivas transformações do campo potencial magnético através das técnicas de filtragens, conjuntamente com dados topográficos ASTER-GDEM (METI-NASA, 2009).

Identificaram-se alinhamentos magnéticos associados com a presença de falhas regionais profundas.

Identificaram-se assinaturas gamaespectrométricas a partir da interpretação dos produtos gráficos geofísicos do processamento dos dados aéreos e terrestres associadas à presença de diferentes litologias constituídas por concentrações anômalas de Potássio (\% K), Uranio (eU ppm) e Tório (eTh ppm).

Identificaram-se domínios magnetométricos em escala regional a partir da interpretação dos mapas obtidos das transformações realizadas ao campo potencial de anomalias magnéticas de intensidade total, associados a feições geológicas e estruturais mapeadas e verificadas no campo através do reconhecimento geológico.

Identificaram-se diferentes unidades litológicas no contexto geológico da área de estudo, através da analise dos dados de susceptibilidade magnética medidos em campo.

\section{Agradecimentos}

Agradecemos de maneira especial a CPRM, por ter disponibilizado os dados aerogeofísicos correspondentes ao Projeto Aerogeofísico Escudo do Rio Grande do Sul (CPRM, 2010), e a UNIPAMPA por ter cedido os equipamentos geofísicos, e por todo o apoio na logística de campo.

\section{Referências}

ASTER Global DEM Validation Summary Report. Disponível http://www.gdem.aster.ersdac.or.jp/index.JTP

em:

CPRM 2010- Serviço Geológico do Brasil. Projeto aerogeofísico Escudo do rio grande do sul: Relatório final do levantamento e processamento dos dados magnetométricos e gamaespectrométricos. Vol. I Texto técnico. Lasa Prospecções S/A,. 260p

CPRM 2008 - Serviço Geológico do Brasil. Mapa Geológico do Rio Grande do Sul 1:750.000. Programa de Geologia do Brasil., DVD. 


\section{Processamento de dados Aerogeofísicos e de Susceptibilidade Magnética em uma 6 Transecta NW}

GEOSOFT. 2005. Data Processing and Analysis System

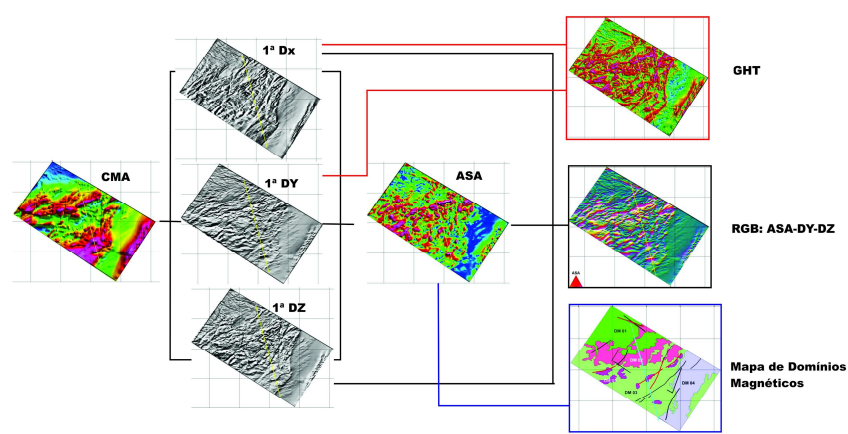

for Earth Science Applications. User Guide.

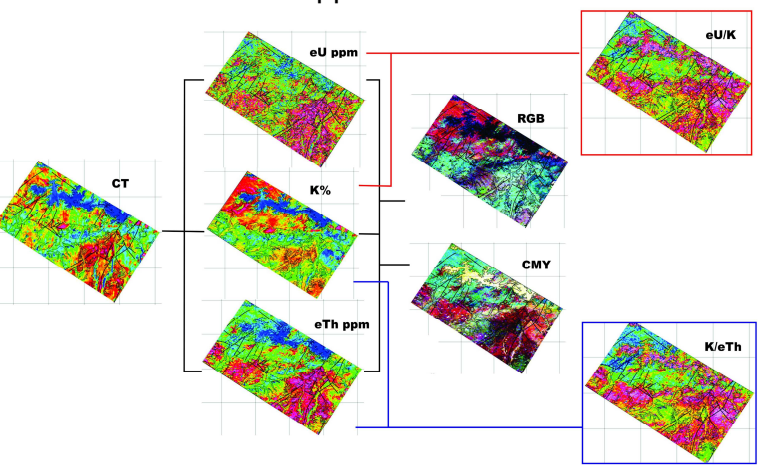

Figura 12. Fluxograma esquemático com o procedimento aplicado ao processamento dos dados aerogeofísicos.

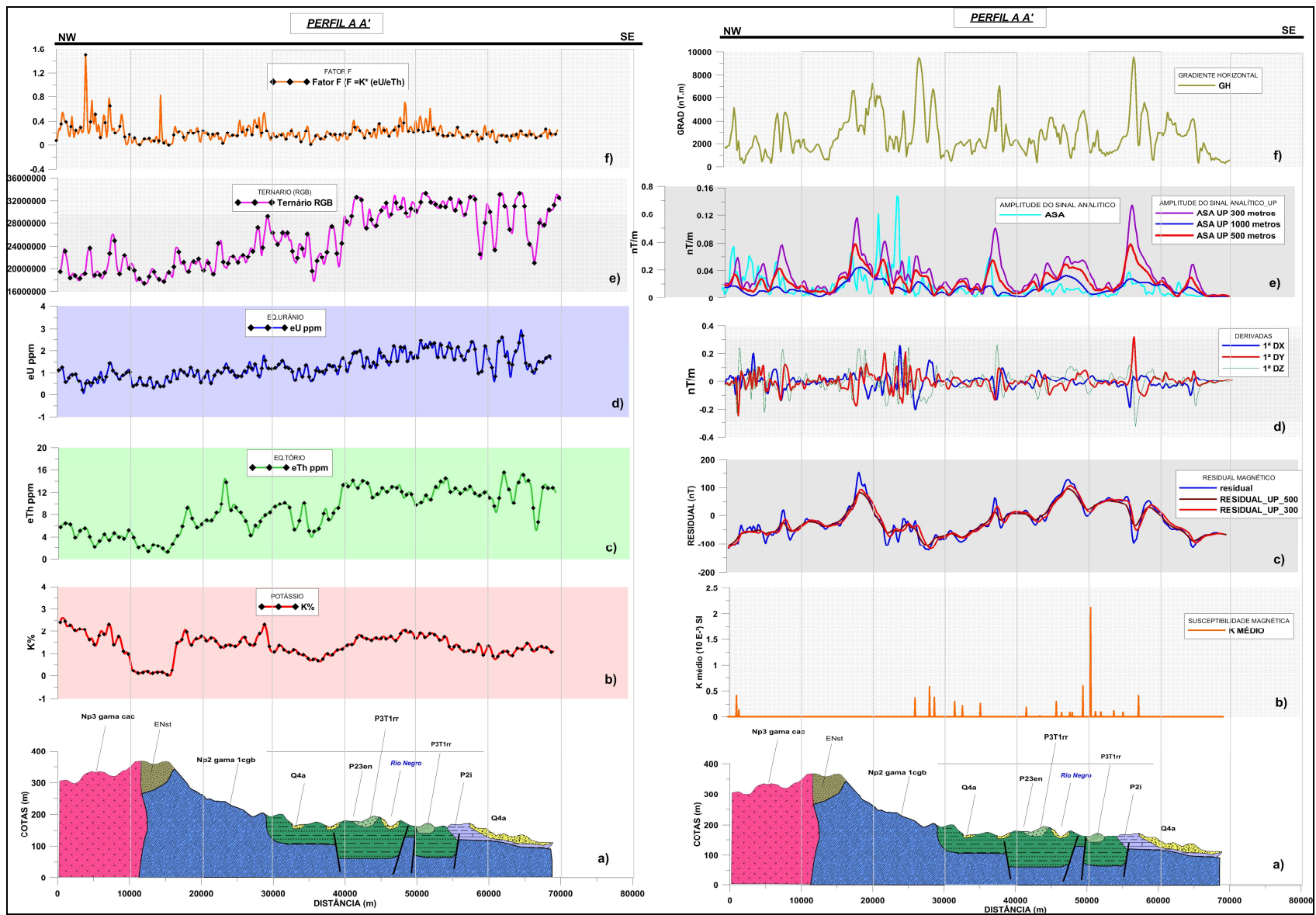

Figura 13. Perfil A-A' gamaespectrometria apresenta: Perfil A-A': a) Informação geológica (CPRM, 2006) com relevo topográfico baseado em dados de altitudes ortométricas do ASTER GDEM (METI-NASA, 2009); b) Canal do K (\%); c) Canal do eTh (ppm); d) Canal do eU (ppm); e) Ternário (RGB); f) Fator (F). Perfil A-A' para magnetometria apresenta: a) Informação geológica (CPRM, 2006) com relevo topográfico baseado em dados de altitudes ortométricas do ASTER GDEM (METI-NASA, 2009); b) Susceptibilidade magnética medida em campo; c) Anomalia residual do Campo Magnético de Intensidade Total; d) 1a Derivadas nas direções "X", "Y" e "Z"; e) Amplitude do Sinal Analítico da anomalia residual do campo magnético de Intensidade Total; f) Gradiente Horizontal da Anomalia residual do Campo Magnético de Intensidade Total. 